\title{
The Cannabinoid Receptor Agonist THC Attenuates Weight Loss in a Rodent Model of Activity-Based Anorexia
}

\author{
Aaron NA Verty'*, Megan J Evetts', Geraldine J Crouch', lain S McGregor², Aneta Stefanidis' \\ and Brian J Oldfield' \\ 'Department of Physiology, Monash University, Clayton, VIC, Australia; ${ }^{2}$ School of Psychology, University of Sydney, Sydney, NSW, Australia
}

\begin{abstract}
Anorexia nervosa (AN) is characterized by anhedonia whereby patients experience little pleasure or reward in many aspects of their lives. Reward pathways and the endocannabionid system have been implicated in the mediation of food intake. The potential to exploit these systems to reverse weight loss is investigated in a rodent model of activity-based anorexia (ABA). The effect of subchronic (6 days) $\Delta^{9}$-tetrahydrocannabinol (THC) treatment $(0.1,0.5$, or $2.0 \mathrm{mg} / \mathrm{kg} /$ day) was assessed on chow and high-fat diet (HFD) intake, body weight, running wheel activity (RWA) as well as thermogenesis in brown adipose tissue (BAT) and lipid metabolism in white adipose tissue (WAT). Limited time availability of food and continuous access to running wheels led to anorexia and significantly reduced body weight. THC treatment $(0.5$ and $2.0 \mathrm{mg} / \mathrm{kg} /$ day $)$ transiently stimulated chow intake with a moderate effect on RWA. THC (2.0 mg/kg/ day) significantly reduced body weight loss and shifted markers of thermogenesis in BAT and lipid metabolism in WAT in directions consistent with reduced energy expenditure and lipolysis. THC $(2.0 \mathrm{mg} / \mathrm{kg} /$ day $)$ combined with HFD, produced a transient increase in food intake, reduction in RWA, attenuation of body weight loss, and changes in markers of thermogensis in BAT and lipolysis in the WAT. These changes were significantly greater than those seen in vehicle (HFD), vehicle (chow), and THC (chow)-treated animals. These data show for the first time the effectiveness of the endocannabinoid system in attenuating the weight loss associated with the development of ABA via a mechanism involving reduced energy expenditure.

Neuropsychopharmacology (20II) 36, 1349-1358; doi:10.1038/npp.201 I.19; published online I6 March 20II
\end{abstract}

Keywords: anorexia nervosa; activity-based anorexia; cannabinoids; thermogenesis; energy expenditure; THC

\section{INTRODUCTION}

Anorexia nervosa (AN) is a psychiatric disorder with complex etiology, resulting in extraordinarily high rates of mortality (12.8\%) and suicide (6\%) (Bulik et al, 2007). It is characterized by an onset during adolescence, predominantly in females, with severe food restriction, food-related anxiety, dramatic body weight loss, increased physical activity, hypothermia, abnormal endocrine function (amenorrhea), and importantly in terms of the present study, severe anhedonia (reduced pleasure) (Davis, 1997; Walsh and Devlin, 1998). Although genetic, biological, sociocultural, and psychological factors undoubtedly have key roles in the pathogenesis of $\mathrm{AN}$, recent evidence points toward a neurobiological contribution to its etiology (Kaye, 2008; Treasure and Campbell, 1994).

In exploring its neurobiological underpinnings, numerous studies have hypothesized a link between disrupted reward circuitry and AN. This link is highlighted by studies

*Correspondence: Dr ANA Verty, Department of Physiology, Monash University, Clatyon, VIC 3800, Australia, Tel: +6I 399058660 ,

Fax: + 6139905 2547, E-mail: aaron.verty@monash.edu

Received 7 September 2010; revised II January 2011; accepted 12 January 2011 showing that patients with AN lead an ascetic life, dislike high-fat foods (Drewnowski et al, 1988; Fernstrom et al, 1994), rate food as negative when hungry (Garfinkel et al, 1979; Santel et al, 2006), and report dysphoric mood following food consumption (Kaye et al, 2003; Vitousek and Manke, 1994). These studies are supported by data showing neuroanatomical abnormalities in AN patients within reward-related regions of the brain including the medial prefrontal cortex (Takano et al, 2001), nucleus accumbens (Kojima et al, 2005; Takano et al, 2001), amygdala, and the thamalus (Takano et al, 2001). Furthermore, neurochemical disruptions associated with the dopaminergic mesolimbic reward system are proposed in the genesis of AN (Barbato et al, 2006; Frank et al, 2005). These reports have focused on the persistently elevated D2 and D3 receptor binding in the anterior ventral striatum, a region classically involved in modulating reward stimuli (Delgado, 2007; Frank et al, 2005) consistent with elevated D2/D3 receptor densities or reduced extracellular DA. In further support for the role of DA in AN, recent studies have shown that antagonism of D1/D2 receptor systems attenuates activity-based anorexia (ABA) (Verhagen et al, 2009a) and DA levels decline over time following exposure to the ABA model (Verhagen et al, 2009b). 
Given the centrality of the anhedonic characteristic in $\mathrm{AN}$, it is possible that the weight loss associated with the disorder can be attenuated by increasing the hedonic value of food. It has been demonstrated in animal models that specific neurotransmitters in the reward pathways can be exogenously stimulated so that complex behaviors such as food seeking and food intake are increased (Berridge, 1996; Berthoud, 2006). Toward this end, overwhelming evidence has demonstrated the role of the endocannabinoid system in reward processing and feeding behavior. The principle psychoactive ingredient in cannabis, $\Delta^{9}$-tetrahydrocannabinol (THC), enhances electrical self-stimulation of the medial forebrain bundle (Gardner et al, 1988), and increases DA levels in the striatum (Malone and Taylor, 1999), neostriatum (Taylor et al, 1988), nucleus accumbens, and medial prefrontal cortex (Chen et al, 1990). With regard to food intake, THC advances feeding episodes in satiated rats (for a review see Kirkham and Williams (2001)), and infusion of the endocannabinoid 2-AG directly into the nucleus accumbens stimulates appetite (Kirkham et al, 2002). Furthermore, the levels of the endocannabinoids $2-\mathrm{AG}$ and anandamide increase in the limbic forebrain of food-deprived rats (Kirkham et al, 2002). Finally, there is suggestive evidence derived from humans showing that the endocannabinoid system is involved in AN. For example, anandamide levels are elevated in symptomatic women an effect that is inversely associated with leptin (Monteleone et al, 2005) while a dysfunctional endocannabinoid system has been linked to disordered attitudes and behaviors associated with AN (Frieling et al, 2009).

Given the powerful role of the endocannabionid system in stimulating reward processes and the apparent poor development of these processes in AN, it is important to test the hypothesis that exogenous administration of cannabinoid type 1 (CB1) receptor agonists can reverse the anorexia displayed in a rodent ABA model. It is widely acknowledged that the development of $\mathrm{ABA}$ in rodents is the most robust animal model of AN where voluntary reduction in food intake, excessive physical activity, and amenhorria mimic the primary behavioral changes observed in the human condition. In the rodent paradigm unrestricted access to running wheels and timed access to food leads to a substantial decrease in food intake and a profound reduction in body weight, resulting in death by starvation if unchecked (Epling et al, 1983; Pirke et al, 1993; Routtenberg and Kuznesof, 1967). Animals maintained on the restricted feeding schedule or access to running wheels alone will escape this debilitating weight loss, which ensues only when they are combined (Epling et al, 1983). Similar to the human condition, the ABA model produces anorexia-like symptoms, primarily in female rodents (Hillebrand et al, 2005a; Pirke $e t$ al, 1993), with the main characteristics of anorexia demonstrated in a number of studies (Atchley and Eckel, 2005; Dixon et al, 2003; Hillebrand et al, 2005a,b, 2006).

Given the alignment of features of the ABA model with the characteristics of human AN, the present study was performed to determine whether rats exposed to the ABA regime can be rescued from subsequent weight loss by the administration of THC. The hypothesis being that the cannabinoid agonist will, by virtue of its actions on brain reward pathways, enhance the hedonic value of food. Given the well-established impact of cannabinoids on energy metabolism (Jbilo et al, 2005; Verty et al, 2009), an alternative hypothesis is that any improvement toward positive energy balance is related to reductions in energy expenditure. This will provide greater insights into the applicability of THC-like compounds in the reversal of AN and a greater understanding of the etiology of the disorder.

\section{MATERIALS AND METHODS}

\section{Animals}

Experimentally naive female Sprague-Dawley rats weighing $\sim 200-220 \mathrm{~g}$ at the beginning of the experiment were used. Rats were housed individually in transparent activity wheel and living chambers (Lafayette Instrument, Lafayette, IN, USA, model no. 80859) lined with dust-free wood chips. Chambers were housed in a climate-controlled room maintained on a $12 \mathrm{~h}: 12 \mathrm{~h}$ reverse light dark cycle (lights off at 1300 hours). Animals had ad libitum access to standard laboratory chow (GR2 Rat and Mouse Cubes, Ridley AgriProducts, Pakenham, Victoria, Australia); Analysis: acid det. fiber $=10.2 \%, \mathrm{NDF}=29.4 \%$, protein $=22.4 \%$, fat $=$ $3.8 \%$, crude fiber $=6.7 \%$, digest. energy $3=16.6 \mathrm{MJ} / \mathrm{kg} \mathrm{DM}$, av. $\mathrm{CHO}=27.9 \%$ ), tap water, and running wheels. At the conclusion of experimental testing, all animals were killed with a lethal dose of sodium pentobarbitone (Lethabarb, Virbac Pty, NSW, Australia).

All animals were treated in accordance with the 'Principles of Laboratory Animal Care' (NIH publication No. 85-23, revised 1985) and the Australian Code of Practice for the Care and Use of Animals for Scientific Purposes. This study was reviewed and approved by the Monash University School of Biomedical Science Animal Ethics Committee. In determining the severity of $\mathrm{ABA}$, animals were allowed to lose a total of $20-25 \%$ of initial body weight before being removed from the experiment and euthanized. Therefore, experiments were conducted for a maximum of 6 days or until it was deemed there were too few animals in a particular treatment group to continue.

\section{Drugs}

THC (a gift from Professor Iain McGregor, University of Sydney) available as a $28-\mathrm{mg} \mathrm{THC} / \mathrm{ml}$ ethanol solution, was first mixed with a few drops of Tween 80 (polyoxyethylene sorbitan monooleate, ICN Biomedicals). The suspension was stirred continuously under a steady stream of nitrogen gas until all ethanol was evaporated. Physiological saline was then added and the solution was stirred until Tween 80 and THC was well dissolved. The final vehicle solution contained $15 \mu \mathrm{l}$ of Tween 80 in $2 \mathrm{ml}$ saline. The vehicle and drug solutions were administered intraperitoneally in a volume of $1 \mathrm{ml} / \mathrm{kg}$.

\section{Running Wheel Activity Measurement}

Each running wheel was connected to an Activity Wheel Counter (Lafayette Instrument) for computer monitoring. Each activity wheel counter on each cage was in turn connected to a USB computer interface for activity wheel counters (Lafayette Instrument); the interface was connected to a computer running an Activity Wheel Software (Lafayette Instrument). The running wheel activity (RWA) 
data were recorded at $15 \mathrm{~min}$ intervals for the entire duration of the experiment.

\section{Dose-Dependent Effect of THC on the Development of ABA}

Animals $(N=28)$ were acclimatized to the activity wheel and living chambers for a period of 10 days with ad libitum food and unlimited access to running wheels. During the acclimatization period, body weight and RWA was measured in order to obtain a stable baseline. At the end of the acclimatization period, animals were divided into four groups: vehicle $(n=6) ; 0.1(n=7) ; 0.5(n=8)$; and 2.0 $(n=7) \mathrm{mg} / \mathrm{kg} /$ day THC. These groups were matched for body weights and RWA. During the acclimatization period, all animals received a vehicle injection $30 \mathrm{~min}$ before the start of the dark cycle.

Day 1 of the treatment represented the start of the $\mathrm{ABA}$ when all food was removed from the cages and rats were injected with either vehicle or THC $(0.1,0.5$, and $2.0 \mathrm{mg} / \mathrm{kg} /$ day) $30 \mathrm{~min}$ before the onset of the dark phase. At the onset of the dark phase, rats were given access to a pre-weighed quantity of food for $90 \mathrm{~min}$. The amount of food provided was greater than that normally ingested during a 24-h period. At the end of this access period, all food was removed and weighed. For the remainder of the time, animals had unlimited access to water and running wheels. RWA was measured every $15 \mathrm{~min}$ as described above while body weight was determined every $24 \mathrm{~h}$.

\section{Combined Effect of THC and a High-Fat Diet on the Developmental of ABA}

Animals $(N=15)$ were acclimatized for 10 days as described above. However, during the last 3 days of acclimatization, rats in addition to chow, were given access to an equal amount of a high-fat diet (HFD) $(2080 \mathrm{~kJ} / 100 \mathrm{~g} ; 25.5 \%$ total fat, $13 \%$ carbohydrate, and $3 \%$ protein) in a compartmentalized hopper giving equal access to each type of food. The HFD was introduced during this time in order to prevent flavor neophobia during drug testing. Animals were then divided into two groups: vehicle $(n=7)$ and $2.0 \mathrm{mg} / \mathrm{kg} /$ day THC $(n=8)$. On day 1 of drug treatment, vehicle or $2.0 \mathrm{mg} / \mathrm{kg} / \mathrm{day}$ THC was injected $30 \mathrm{~min}$ before the start of the dark phase. At the onset of the dark phase, rats were given access to an equal amount in kilojoules of chow and HFD for $90 \mathrm{~min}$. At the end of the food access period, all food was removed and weighed. Body weight and RWA were measured as described above.

\section{Effect of THC on Markers of Thermogenesis and Lipid Metabolism}

At the end of each experiment, rats were killed by decapitation following a brief exposure to $\mathrm{CO}_{2}$ and brown adipose tissue (BAT), inguinal white adipose tissue (iWAT), and retroperitoneal white adipose tissue (rWAT) were removed. The white fat pads represented subcutaneous and abdominal depots, respectively. The BAT was frozen immediately after removal while the rWAT and iWAT were first weighed and only the rWAT was kept for further analysis. Protein from the BAT and rWAT was extracted as previously described (Verty et al, 2009). In all, $10 \mu$ g protein was loaded onto a 4-20\% SDS-polyacrylamide gel and transferred onto a nitrocellulose membrane (Schleicher and Schuell, Bartell Instruments, Australia). Adequate transfer was assessed by staining the membrane with $2 \%$ Ponceau S. The membrane was blocked with $5 \%$ non-fat dry milk powder in Tris- buffered saline/1\% Tween 20 (Sigma, St Louis, USA) for $1 \mathrm{~h}$ and incubated overnight at $4{ }^{\circ} \mathrm{C}$ with the primary antibody for UCP1 in BAT (UCP11-A, Alpha Diagnostics International, San Antonio, TX; Rabbit polyclonal, diluted 1:250) in 5\% BSA in Tris-buffered saline/ Tween 20 solution) and fatty acid synthase (FAS; Sigma Aldrich, Sydney, Australia; Rabbit polyclonal, diluted 1:2000), Adipose Tissue Triglyceride Lipase (ATGL; Cell Signaling Technologies, Danvers, MA, USA, Rabbit polyclonal; diluted 1:1000), and comparative gene identification58 (CGI-58; Abnova, Neihu District., Taipei City, Taiwan, Mouse monoclonal, diluted 1:500) in rWAT. Following secondary antibody incubation using anti-rabbit HRP (1:2000 for UCP1, FAS, and ATGL) and anti-mouse HRP (1:500 for CGI-58) protein expression signals were visualized by chemiluminescence using the LumiGlo kit (Cell Signalling Technologies, MA, USA) on Kodak Biomax X-ray film (Kodak, ML, USA). Relative densities of protein bands were assessed using a densitometer and SynGene Gene Tools analysis software (SynGene Laboratories, MD, USA).

\section{Statistical Analysis}

The RWA measurement, body weight, and amount of food consumed $(\mathrm{g})$ were used as dependent variables and analyzed separately. Data for the baseline RWA count, body weight, and food consumed, were analyzed using paired $t$-tests or repeated measures ANOVAs. Data for the RWA were collapsed into 1-h time intervals. These data were further averaged for each time interval, for each rat in each treatment group, for the duration of the treatment period to give a 24 -h variation in RWA. Time was treated as a factor. Repeated measures (treatment by time) ANOVAs with time being the repeated measure was conducted on each dependent variable. Similarly, body weight for each day for each group was averaged and analyzed using a repeated measures (treatment by day) ANOVA with day as the repeated factor. Daily food intake was measured using either a $t$-test or a one-way ANOVA. Where significant main effects were found, pairwise comparisons were conducted using Bonferroni adjustments for multiple comparisons. Mauchly's W was computed to check for violations of the sphericity assumptions. When Mauchly's W test was significant, the Greenhouse-Geisser correction was applied. For western blot analysis and iWAT and rWAT weights, a one-way ANOVA was performed to determine if the protein expression and fat pad weights of the various groups were significantly differentially affected by the treatment.

\section{RESULTS}

\section{Dose-Dependent Effect of THC on the Development of ABA}

The mean quantity of food consumed and RWA during the entire acclimatization period did not differ significantly 
between the treatment groups. As a result, there was no significant difference in the mean body weights of each treatment group at the start of the experiment. It should be noted that two animals treated with vehicle reached the $20-25 \%$ weight loss criterion on day 5 and hence were removed from the experiment and not injected on day 6 .

During the ABA phase, animals were injected with either vehicle or different doses of THC $(0.1,0.5$, or $2.0 \mathrm{mg} / \mathrm{kg} / \mathrm{day})$ $30 \mathrm{~min}$ before the start of the dark phase and food intake measured $90 \mathrm{~min}$ after the start of the dark phase. At the end of the 90-min food access period, a significant transient increase in feeding was observed only in those animals administered 0.5 and $2.0 \mathrm{mg} / \mathrm{kg} /$ day THC on day $1\left(\mathrm{~F}_{(1,27)}=\right.$ 12.99; $P<0.05)$ of treatment. This effect was not evident on subsequent days of treatment at which time the groups were indistinguishable from each other (Figure 1a).

Average daily $24 \mathrm{~h}$ RWA showed a phasic response represented by an increase in activity occurring during the dark phase and a decrease during the light phase. The pattern of RWA observed during the light phase showed a non-significant increase in anticipatory RWA at least $3 \mathrm{~h}$ before the onset of the dark phase (Figure $1 \mathrm{~b}$ ). Average RWA for the entire experimental period highlighted a delay in the onset of activity in the dark phase in THC-treated animals as well as a reduction in the amplitude of RWA compared with vehicle. This effect was present in all THC-treated animals but was most pronounced and only reached significance in the group given $0.5 \mathrm{mg} / \mathrm{kg} / \mathrm{day}$ THC $\left(\mathrm{F}_{(1,27)}=42.63 ; P<0.05\right)$ (Figure $\left.1 \mathrm{~b}\right)$. Interestingly, the dose of THC $(0.5 \mathrm{mg} / \mathrm{kg} /$ day $)$ that significantly reduced RWA did not attenuate the body weight loss when compared with vehicle-treated animals. In fact, the 0.1 and $0.5 \mathrm{mg} / \mathrm{kg} /$ day THC-treated animals lost $24 \%$ of their starting weight that was similar to the weight lost by the vehicle-treated group (Figure 1c). A significant attenuation of weight loss was seen only with the high dose of THC $(2.0 \mathrm{mg} / \mathrm{kg} /$ day $)$. By comparison, these animals lost only $15 \%$ of their starting body weights $\left(\mathrm{F}_{(1,27)}=21.03 ; P<0.05\right)$. The attenuation of body weight by $2.0 \mathrm{mg} / \mathrm{kg} /$ day THC was significant for the entire treatment period when compared with vehicle, 0.1 , and $0.5 \mathrm{mg} / \mathrm{kg} /$ day THC (treatment by time interaction: $\left.\left(\mathrm{F}_{(4,41)}=2.93 ; P<0.05\right)\right)($ Figure $1 \mathrm{c})$.

\section{Combined Effect of THC and HFD on the Development of ABA}

Given the effectiveness of $2.0 \mathrm{mg} / \mathrm{kg} / \mathrm{day}$ THC in attenuating body weight loss without affecting RWA, we used this dose in all subsequent studies.

The amount of all types of food consumed, RWA, and body weight during acclimatization period did not differ significantly between the treatment groups. Furthermore, there was no significant change in RWA due to the introduction of a HFD when compared with the baseline RWA in animals fed a chow diet. When food intake was measured on each day of the experimental period, the $2.0 \mathrm{mg} / \mathrm{kg} / \mathrm{day}$ dose of THC significantly stimulated chow $\left(\mathrm{F}_{(1,14)}=10.21\right.$; $P<0.05)$ (Figure 2a) and $\operatorname{HFD}\left(\mathrm{F}_{(1,14)}=13.65 ; P<0.05\right)$ (Figure $2 \mathrm{~b}$ ) intake on days 1 and 2. Over the entire experimental period (6 days), both groups (vehicle and THC) significantly increased their average HFD intake compared with chow; however, there was no difference in the average a

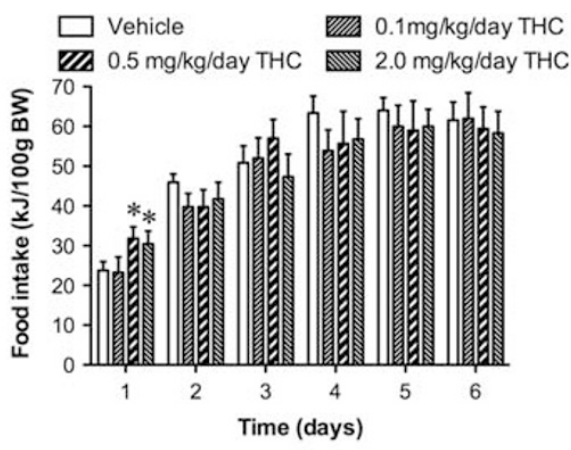

b
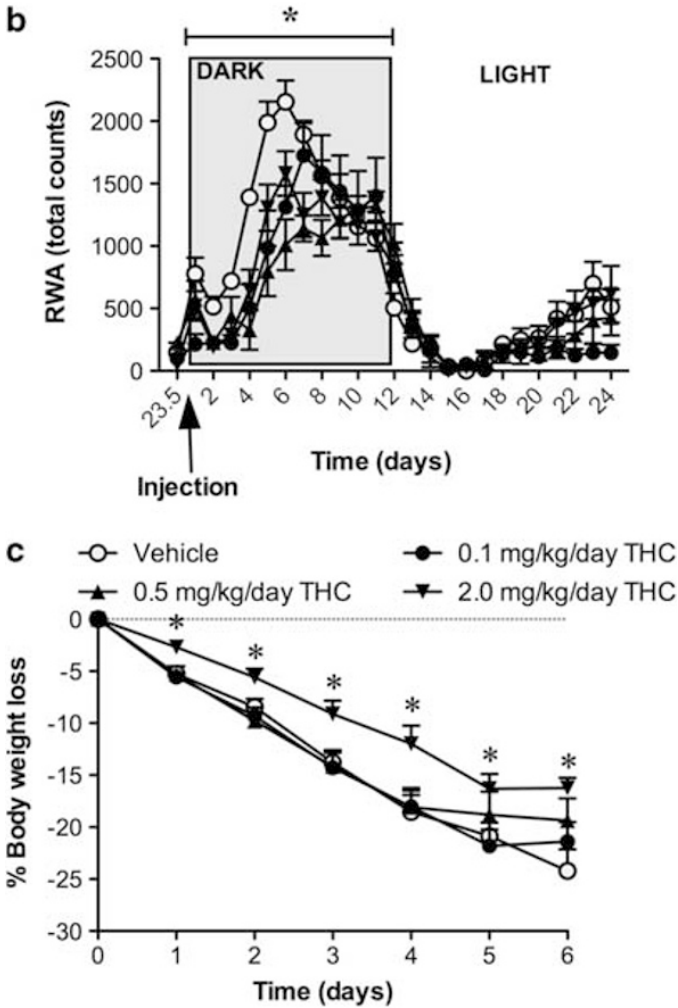

Figure I Dose-response curves demonstrating total energy consumed (a), total RWA (b), and percentage weight loss compared with baseline (c) in food-restricted rats treated with vehicle or THC $(0.1,0.5$, or $2.0 \mathrm{mg} / \mathrm{kg} / \mathrm{day})$. Data for RWA represent the daily mean of the activity at each time point for each treatment group giving a 24-h variation in RWA. Results are expressed as mean \pm SEM. $* P<0.05$ vs vehicle.

daily intake between the vehicle and THC groups fed either chow or HFD.

A significant delay in the onset of RWA during 2, 3, and $4 \mathrm{~h}$ of the dark phase was seen when $2.0 \mathrm{mg} / \mathrm{kg} /$ day THC was administered compared with vehicle $\left(\mathrm{F}_{(1,14)}=19.51\right.$; $P<0.05)$. Following this initial delay, both the vehicle and THC-treated animals were indistinguishable for the remainder of the measurement period (Figure 3a). Similar to the RWA in experiment 1 , there was an increase in anticipatory RWA in the last $3 \mathrm{~h}$ of the light phase in each of the two treatment groups (Figure 3a).

With regard to body weight, vehicle (HFD)-treated animals lost weight at a steady rate reaching $15 \%$ body weight loss on average after 6 days. In comparison, the $2.0 \mathrm{mg} / \mathrm{kg} /$ day THC (HFD) animals lost significantly less 

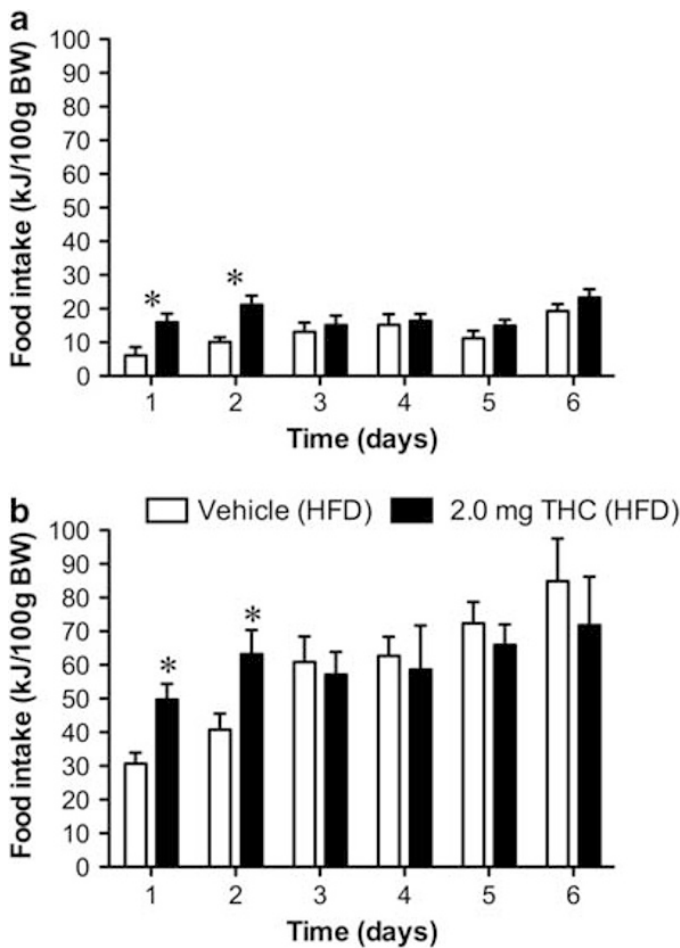

Figure 2 Daily energy intake in rats given restricted access to food and treated with either vehicle or THC $(2.0 \mathrm{mg} / \mathrm{kg} /$ day $)$. (a) Consumption of rat chow. (b) Consumption of a high-fat diet. Results are expressed as mean \pm SEM. $* P<0.05$ vs vehicle.

weight (9\%) compared with controls $\left(\mathrm{F}_{(1,14)}=21.03\right.$; $P<0.05)$. This inhibition of weight loss in THC (HFD) animals was evident on days $2-6$ of the experimental period (treatment by time interaction: $\left(\mathrm{F}_{(4,32)}=5.73 ; P<0.05\right)$ ) (Figure 3b).

It is interesting to note that $2 \mathrm{mg} / \mathrm{kg} /$ day THC (chow) animals (Figure 1c) lost the same amount of weight $(15 \%)$ as the vehicle (HFD) animals (15\%) (Figure $3 \mathrm{~b}$ ). Amalgamating the data derived from vehicle (chow) and $2 \mathrm{mg} / \mathrm{kg} /$ day THC (chow)-treated animals (Figure 1c) with vehicle (HFD) and $2 \mathrm{mg} / \mathrm{kg} / \mathrm{day}$ THC (HFD)-treated animals (Figure 3b) shows that the combination of HFD and THC produces a significantly greater attenuation of body weight loss ( $9 \%$ body weight loss from starting body weight) when compared with the vehicle (chow), THC (chow), and vehicle (HFD) animals (Figure 4) $\left(\mathrm{F}_{(1,28)}=35.62 ; P<0.05\right)$. This attenuation of weight loss was significantly greater than would be attributed to the attenuation of weight loss observed with vehicle (HFD) and THC (chow) animals (treatment by time interaction: $\left(\mathrm{F}_{(4,41)}=8.95 ; P<0.05\right)$ ). It should be noted that a one-way ANOVA analyzing the body weights at the start of the ABA of the two cohort of animals used to generate the data set shown in Figures $1 \mathrm{c}$ and $3 \mathrm{~b}$ were not significantly different from each other.

\section{Effect of THC on WAT Weight and the Expression of Markers of Thermogenesis and Lipid Metabolism in the Development of ABA}

Following subchronic treatment with THC or vehicle in conjunction with different diets as described above, the
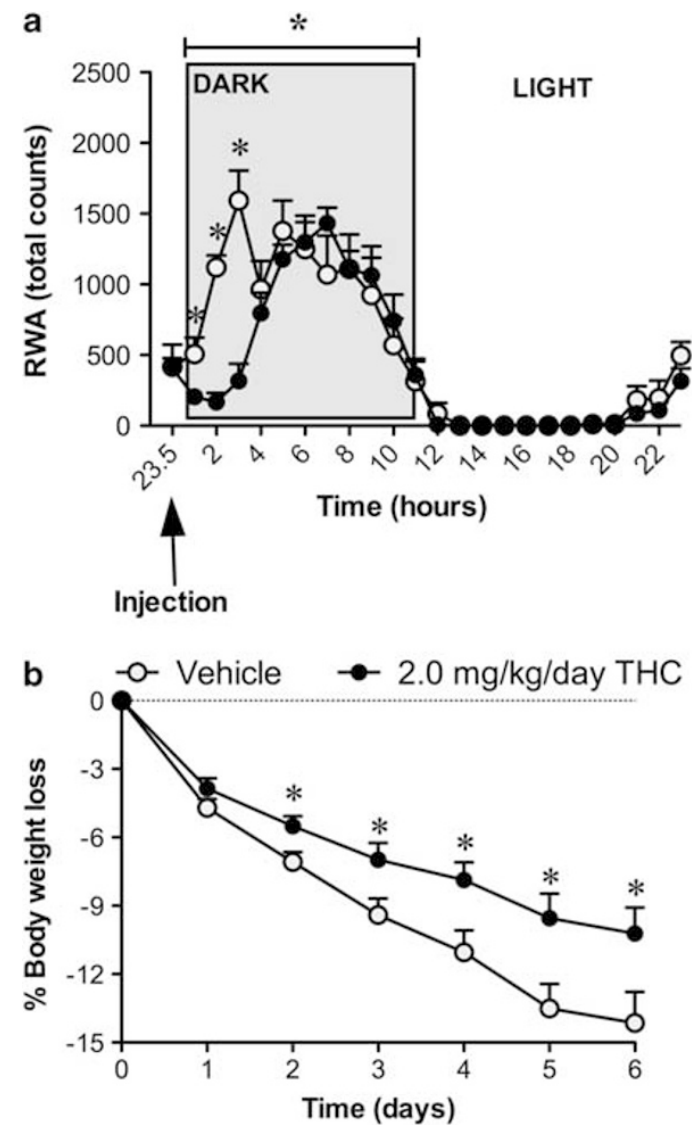

Figure 3 Daily running wheel activity (a) and body weight loss (b) measured in rats given either vehicle or THC $(2.0 \mathrm{mg} / \mathrm{kg} / \mathrm{day})$. Data for RWA represent the daily mean of the activity at each time point for each treatment group giving a 24-h variation in RWA. Results are expressed as mean \pm SEM. ${ }^{*} P<0.05$ vs vehicle.

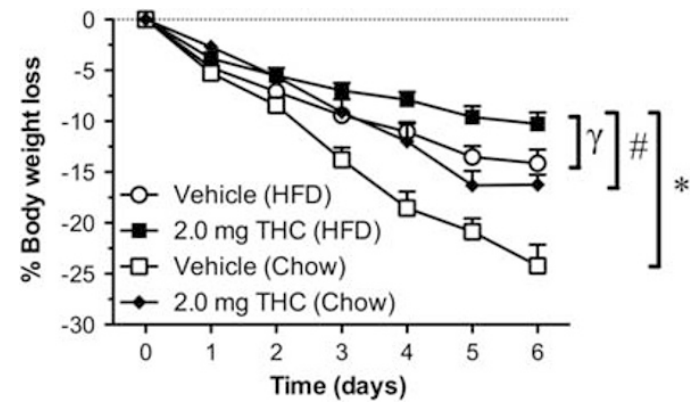

Figure 4 Comparison of body weight loss in rats given vehicle or THC $(2.0 \mathrm{mg} / \mathrm{kg} / \mathrm{day})$ and fed either chow or high-fat diet (HFD). Results expressed as mean \pm SEM. * $P<0.05$ vs vehicle (chow); ${ }^{\#} P<0.05$ vs THC (chow); ${ }^{\gamma} P<0.05$ vs vehicle (HFD).

weight of the rWAT in the THC (chow) and vehicle (HFD)treated rats was significantly elevated from control (vehicle (chow)) levels (Figure 5a). Interestingly, the combination of HFD and THC produced a significantly greater preservation of rWAT when compared with THC (chow) and vehicle $(\mathrm{HFD})$-treated rats $\left(\mathrm{F}_{(1,10)}=5.17 ; P<0.05\right)$ (Figure 5a). No significant change was observed in the iWAT (Figure 5b). 


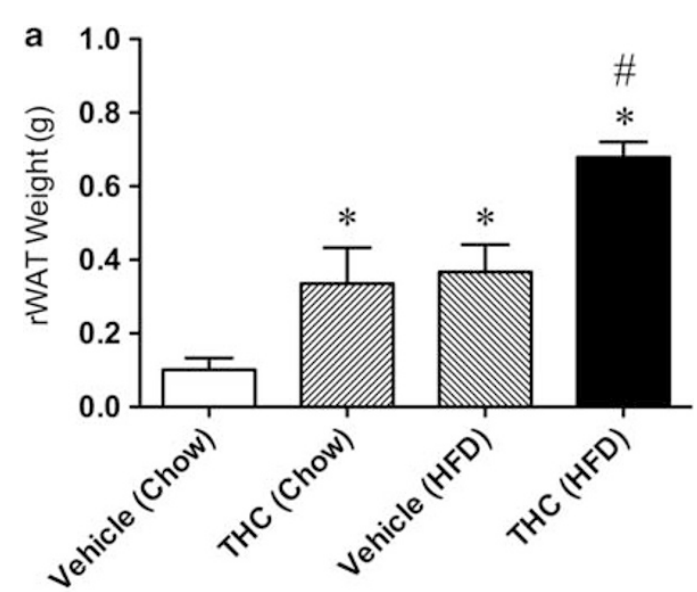

availability of food is combined with access to running wheels (Atchley and Eckel, 2005; Dixon et al, 2003; Hillebrand et al, 2005a,b, 2006). This was characterized by hypophagia, hyperactivity, and a rapid reduction of body weight. These data are also supportive of a role for THC in increasing food intake, albeit transiently, which is consistent with the previous demonstration of enhanced intake of highly palatable foods following acute treatment with THC (Koch, 2001). Importantly, the data presented here show for the first time the efficacy of THC $(2.0 \mathrm{mg} / \mathrm{kg} /$ day $)$ in retarding the progression of $\mathrm{ABA}$. The attenuating effect of THC on ABA was significantly amplified when a high fat, palatable diet was introduced in conjunction with THC treatment. Furthermore, the expression of genes associated with thermogenesis in BAT and lipid metabolism in WAT shifted in directions consistent with a reduction in energy expenditure and lipolysis.

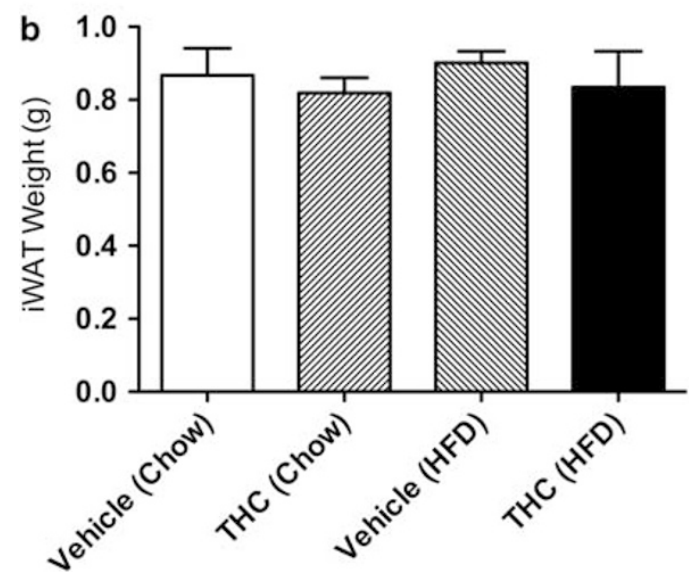

Figure 5 Total weight of retroperitoneal white adipose tissue (rWAT) (a) and inguinal white adipose tissue (iWAT) (b) in rats fed either standard rat chow or a high-fat diet and treated with either vehicle or THC $(2.0 \mathrm{mg} / \mathrm{kg} / \mathrm{day})$. ${ }^{*} P<0.05$ vs vehicle (chow); ${ }^{\#} P<0.05$, vs THC (chow) and vehicle (HFD).

Western blot analysis was used to detect changes in the markers of thermogenic activity (UCP1 protein) in BAT and lipogenesis (FAS) or lipolysis (ATGL and CGI-58 protein) in the rWAT in ABA vehicle (chow), THC (chow), vehicle (HFD), and THC (HFD) animals. A significant reduction in UCP1 protein expression $\left(\mathrm{F}_{(1,10)}=3.87 ; P<0.05\right)$ was seen in THC (chow) and vehicle (HFD)-treated animals when compared with vehicle (chow). This reduction was further enhanced when THC was given in conjunction with HFD (Figure 6a). In a similar vein, measures of lipolysis (ATGL (Figure 6c) and CGI-58 (Figure 6d)) were reduced in THC (chow) and vehicle (HFD) treated compared with vehicle (chow) animals. This reduction in lipolysis compared with vehicle (chow) treatment during $\mathrm{ABA}$ underwent an even more dramatic reduction when the THC and HFD regimes were combined (treatment by time interaction: UCP1 $\left(\mathrm{F}_{(1,10)}=5.03 ; P<0.05\right)$; ATGL $\left(\mathrm{F}_{(1,10)}=4.31 ; P<0.05\right)$, and CGI-58 $\left.\left(\mathrm{F}_{(1,10)}=3.84 ; P<0.05\right)\right)$ (Figure $6 \mathrm{a}, \mathrm{c}$, and $\mathrm{d}$ ). No shift in the expression of FAS was observed under any condition (Figure 6b).

\section{DISCUSSION}

The present findings support previous descriptions of a robust $\mathrm{ABA}$ displayed in rats when restricted time

The conservation of fat that resulted from THC treatment during $\mathrm{ABA}$ was registered only in the abdominal compartment and was primarily due to a reduction in lipolytic activity rather than an elevation of lipogenesis. The levels of fat preservation following THC administration were matched by exposure to a HFD. In this respect, the link between ingestion of HFD and increased abdominal fat mass and even retardation of ABA-induced weight loss is not unexpected; however, the increase in caloric intake due to the diet on any single day of treatment was modest only reaching significance when considered over the whole 6-day period (data not shown). The possibility exists that acute exposure to high-caloric diet per se prompted sympathetic nerve-mediated changes in lipolysis. Such changes have been noted in heart rate and blood pressure in the short term following exposure to HFD (Antic et al, 2000). Furthermore, shifts in sympathetic nerve activity have even been recorded coincident with the start of such a diet well before any possibility exists for a change in fat content (Burke, Prior, Head, Armitage, and Eikelis, personal communication). This explanation is not straightforward, however, as in both the examples cited above and in our understanding of diet-induced thermogenesis, high-calorie diets lead to elevation in sympathetic nerve activity. However, in the present experiments, the HFD when given in the context of the ABA leads to reduced lipolysis and BAT thermogenesis consistent with a reduced sympathetic tone.

What is clear is that the combination of HFD and THC treatment leads to a profound positive effect on energy balance with reductions in lipolysis, thermogenesis (UCP1), and $\mathrm{ABA}$-induced weight loss. The observations in relation to THC and thermogenesis are consistent with previous studies, showing that the administration of the CB1 receptor agonist WIN 55212-2 reduces the expression of UCP1 in the BAT (Perwitz et al, 2006). In addition, other studies exploring the role of the endocannabinoid system have shown that blockade of cannabinoid receptors induces transcriptional changes consistent with enhanced lipolysis and increased energy expenditure (Jbilo et al, 2005), including an elevation of thermogenic activity in BAT (Verty et al, 2009). As CB1 receptors are present and functional in the CNS (Herkenham et al, 1991a,b) and in white (Fisk et al, 2006) and brown (Jbilo et al, 2005) adipose tissues, it is conceivable that the effects observed in the present 

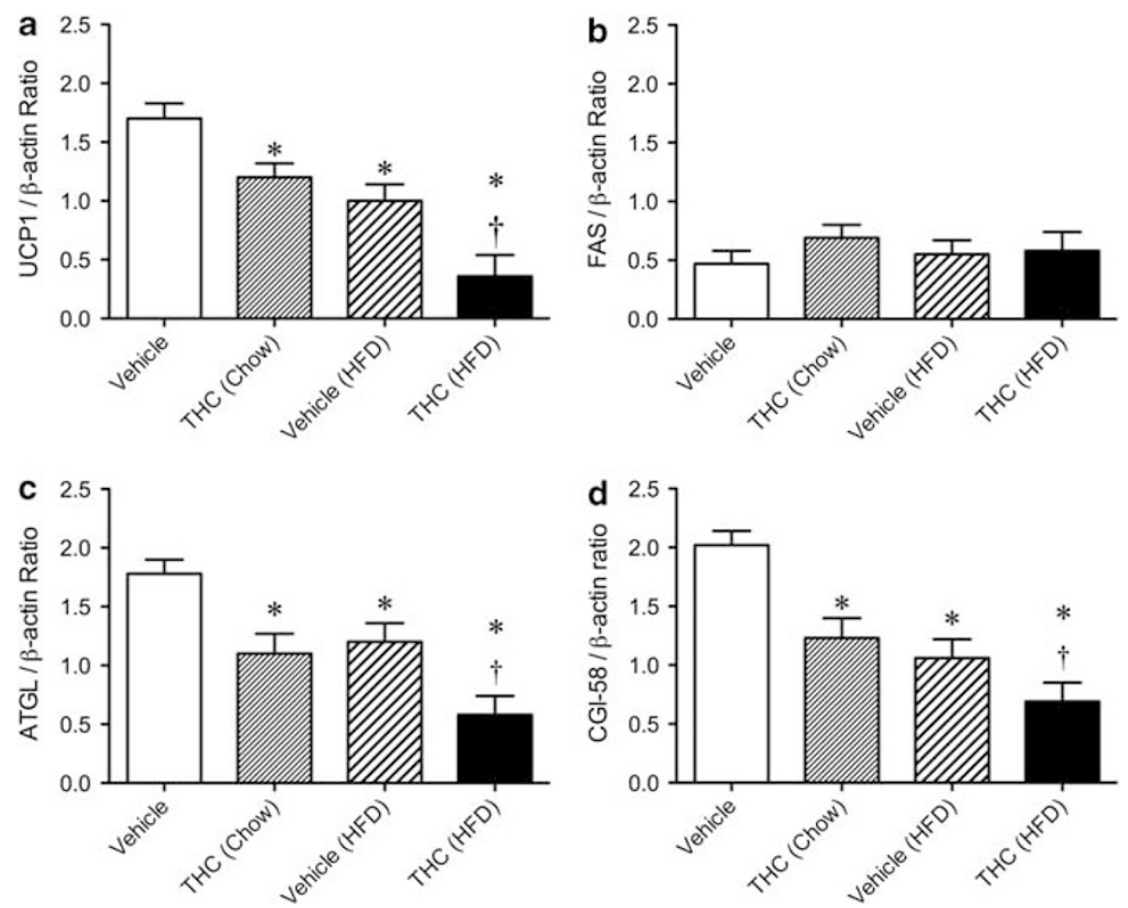

Figure 6 Western blot detection of UCPI protein expression in brown adipose tissue (a) and FAS (b), ATGL (c), and CGI-58 (d) protein expression in the white adipose tissue obtained from rats fed either rat chow or a high-fat diet and treated with vehicle or THC ( $2.0 \mathrm{mg} / \mathrm{kg} / \mathrm{day})$ over 6 days. Signals from each animal quantified and peptide expression shown as a ratio of $\beta$-actin (housekeeping) following vehicle $(n=7)$ and $2.0 \mathrm{mg} / \mathrm{kg} / \mathrm{day}$ THC ( $n=8)$. Results are expressed as mean \pm SEM. ${ }^{*} P<0.05$ vs vehicle; ${ }^{\dagger} P<0.05$ vs THC (chow) and vehicle (HFD).

experiments of THC on lipid metabolism and thermogenesis are either centrally or peripherally mediated.

The THC-induced shifts in the markers of lipogenesis (FAS), lipolysis (ATGL and CGI-58), and thermogenesis (UCP1) are consistent with a reduction in catabolic processes in white and brown fat that collectively enhance weight gain and resistance to the ABA. The mechanisms by which THC impacts on these processes in different fat depots are, as yet, unclear. One possibility is that the changes in thermogensis and lipolysis could be mediated via cannabinoid actions on AMP-activated protein kinase (AMPK). It is well established that AMPK activation stimulates UCP1 expression (Rossmeisl et al, 2004) inhibits lipogenesis and stimulates lipid oxidation (Lihn et al, 2004). This has been demonstrated within the starvation context where $48 \mathrm{~h}$ food deprivation significantly elevates AMPK activity in the adipose tissue that is diminished following re-feeding (Assifi et al, 2005). Furthermore, feeding animals a HFD has been shown to significantly inhibit AMPK activity (Liu et al, 2006). Recently, it has been shown that THC inhibits AMPK in the abdominal WAT (Kola et al, 2005). Thus, it is possible that within the ABA model, THC administration alone or in combination with the high-fat food inhibits AMPK activity thereby mimicking a re-feeding state leading to increased conservation of the adipose depots shown in Figure 5.

Considering that THC reliably produces hypothermia (De Vry et al, 2004; McKinney et al, 2008), it is conceivable that THC-induced decrease in body temperature could lead to a reduction in BAT temperature-associated thermogenic activity. However, we have shown that BAT temperature varies in the same direction as, but is temporally independent of, shifts in core temperature (Stefanidis et al, 2009). It is likely that the same relationship between the two measures exists in the present experiment. Furthermore, tolerance to the hypothermic effect of THC develops within 2-3 days (De Vry et al, 2004; McKinney et al, 2008), while THC was administered in the current study over a period of 6 days, suggesting that the continued elevation of UCP1 protein is indicative of long-term activation of thermogenesis (Verty et al, 2009) that is independent of core temperature.

The finding that administration of 0.5 and $2.0 \mathrm{mg} / \mathrm{kg} /$ day THC significantly stimulates appetite in ABA animals given restricted access to chow for $90 \mathrm{~min}$ complements previous studies showing a stimulation of food intake in normal, non-ABA rats (Verty et al, 2004, 2005; Williams and Kirkham, 2002a,b). The lack of effect on food intake seen on days 2, 3, 4, 5, and 6 (see Figure 1a) supports the transient nature of hyperphagia following subchronic administration of THC.

Despite all of these shifts in metabolic parameters, body weight is the essential index determining the progression of ABA (Siegfried et al, 2003). Using this index, the data derived here show that THC $(2.0 \mathrm{mg} / \mathrm{kg} /$ day $)$ produces a significant attenuation of body weight loss associated with AN in animals fed either a chow or a HFD that is independent of any meaningful effect on RWA. Although the $2.0 \mathrm{mg} / \mathrm{kg} / \mathrm{day}$ THC-treated rats fed a HFD did show a significant attenuation of RWA at 2,3 , and $4 \mathrm{~h}$ when compared with vehicle, this effect was indistinguishable from vehicle for the remainder of $21 \mathrm{~h}$ of RWA measurement (Figure 3a). This initial reduction in activity mirrors previous studies showing hypoactivity in response to acute 
THC administration (De Vry et al, 2004; McKinney et al, 2008). However, the initial retardation in the onset of RWA (Figures $1 \mathrm{~b}$ and $3 \mathrm{a}$ ) is unlikely to have accounted for the robust attenuation of body weight loss observed. This is an important observation given the fact that previous studies using the $\mathrm{ABA}$ model have relied almost completely on the sedative actions of agents such as the antipsychotic drug, olanzapine to sever the nexus between weight loss and excessive exercise (Hillebrand et al, 2005b). This nexus is also an important focal point for therapies in the human condition (Bratland-Sanda et al, 2010). The combination of $2.0 \mathrm{mg} / \mathrm{kg} /$ day THC and a HFD produced a significantly greater attenuation of weight loss that was different than would be attributed to the attenuation of weight loss observed with vehicle-treated high fat and THC-treated chow fed animals (Figure 4). Notably, a number of studies have shown that cannabinoids enhance the intake of palatable diets such as those high in fat and salt content (Koch, 2001; Mahler et al, 2007), suggesting a possible influence on the reward or hedonic value of food. It is tempting to suggest that the attenuation of weight loss observed following the administration of THC alone or in combination with a HFD was due to increased hedonic tone. However, our data points toward reduced energy expenditure in the form of decreased thermogenesis (UCP1 expression) and reduced lipolysis. That being said, it is important to note that reduced hedonia has an important part in the pathophysiology of AN and it remains to be more rigorously determined as to the exact role of the mesolimbic dopaminergic system in this disease.

The findings reported here are contrary to a recent study showing an increase in mortality rate in male $\mathrm{ABA}$ mice given THC (Lewis and Brett, 2010). The reasons for these discrepant findings are not clear but may reflect important differences in the way cannabinoid ligands produce contrasting results in rats and mice. For example, in mice, cannabinoid receptor 1 agonists are anxiolytic while in rats they are anxiogenic (Berrendero and Maldonado, 2002; Patel and Hillard, 2006; Valjent et al, 2002). It is quite possible that these or other species differences exist within the ABA model and the effect of drugs on it and could explain the improved survival in our study $v s$ the increased mortality shown by Lewis and Brett (2010).

Within the human context, the efficacy of THC in reversing anorexia associated with cancer chemotherapy and HIV has been well established (Beal et al, 1995, 1997; Jatoi et al, 2002). However, the evidence for the effectiveness of THC in attenuating the symptoms of AN is equivocal. Specifically, a randomized double-blind study comparing THC with a placebo (diazepam) failed to show any weight gain in patients with AN (Gross et al, 1983). These results need to be considered with caution as both the THC and placebo-treated subjects gained equal amounts of weight $(\sim 12 \%)$. This is not surprising as the placebo used (diazepam) consistently stimulates food intake and body weight in both animals (Naruse, 1994; Patel and Ebenezer, 2008) and humans (Frisbie and Aguilera, 1995). Therefore, the conclusion drawn regarding the lack of efficacy of THC treatment in AN needs closer examination.

A recent study using the ABA model has demonstrated the efficacy of a HFD in rescuing rodents from anorexia (Brown et al, 2008). However, feeding a HFD to human AN patients runs contrary to the characteristics of the disorder and attempts to do this have been shown to heighten anxiety associated with eating a high-caloric diet (Boutelle, 1998). In this regard, THC which is a known anxiolytic would, at least theoretically, represent an appropriate combination therapy with a HFD in the treatment of AN.

In conclusion, these data establish for the first time the effectiveness of THC in rescuing animals from profound body weight loss associated with the development of $\mathrm{ABA}$, independent of physical activity, which is enhanced if allowed access to highly palatable foods. These results from the animal-based model of AN highlight the potential of cannabinoids and of the endocannabinoid system in the treatment of human anorexia.

\section{ACKNOWLEDGEMENTS}

ANAV is also the recipient of the NHMRC Peter Doherty Postdoctoral Research Fellowship. This study was supported by a grant from the National Health and Medical Research Council (NHMRC) to Professor Oldfield and Dr Verty (Grant number 3160479).

\section{DISCLOSURE}

The authors declare no conflict of interest.

\section{REFERENCES}

Antic V, Kiener-Belforti F, Tempini A, Van Vliet BN, Montani JP (2000). Role of the sympathetic nervous system during the development of obesity-induced hypertension in rabbits. $\mathrm{Am} \mathrm{J}$ Hypertens 13: 556-559.

Assifi MM, Suchankova G, Constant S, Prentki M, Saha AK, Ruderman NB (2005). AMP-activated protein kinase and coordination of hepatic fatty acid metabolism of starved/ carbohydrate-refed rats. Am J Physiol Endocrinol Metab 289: E794-E800.

Atchley DP, Eckel LA (2005). Fenfluramine treatment in female rats accelerates the weight loss associated with activity-based anorexia. Pharmacol Biochem Behav 80: 273-279.

Barbato G, Fichele M, Senatore I, Casiello M, Muscettola G (2006). Increased dopaminergic activity in restricting-type anorexia nervosa. Psychiatry Res 142: 253-255.

Beal JE, Olson R, Laubenstien L, Morales JO, Bellman P, Yangco B et al (1995). Dronabinol as a treatment for anorexia associated with weight loss in patients with AIDS. J Pain Symptom Manage 10: 89-97.

Beal JE, Olson R, Lefkowitz L, Laubenstein L, Bellman P, Yangco B et al (1997). Long-term efficacy and safety of dronabinol for acquired immunodeficiency syndrome-associated anorexia. J Pain Symptom Manage 14: 7-14.

Berrendero F, Maldonado R (2002). Involvement of the opioid system in the anxiolytic-like effects induced by Delta(9)-tetrahydrocannabinol. Psychopharmacology (Berl) 163: 111-117.

Berridge KC (1996). Food reward: brain substrates of wanting and liking. Neurosci Biobehav Rev 20: 1-25.

Berthoud HR (2006). Homeostatic and non-homeostatic pathways involved in the control of food intake and energy balance. Obesity (Silver Spring) 14(Suppl 5): 197S-200S.

Boutelle KN (1998). The use of exposure with response prevention in a male anorexic. J Behav Ther Exp Psychiatry 29: 79-84.

Bratland-Sanda S, Sundgot-Borgen J, Rø $\varnothing$, Rosenvinge JH, Hoffart A, Martinsen EW (2010). Physical activity and exercise dependence 
during inpatient treatment of longstanding eating disorders: an exploratory study of excessive and non-excessive exercisers. Int J Eat Disord 43: 266-273.

Brown AJ, Avena NM, Hoebel BG (2008). A high-fat diet prevents and reverses the development of activity-based anorexia in rats. Int J Eat Disord 41: 383-389.

Bulik CM, Slof-Opt Landt MC, Van Furth EF, Sullivan PF (2007). The genetics of anorexia nervosa. Annu Rev Nutr 27: 263-275.

Chen JP, Paredes W, Li J, Smith D, Lowinson J, Gardner EL (1990). $\Delta^{9}$-tetrahydrocannabinol produces naloxone-blockable enhancement of presynaptic basal dopamine efflux in nucleus accumbens of conscious, freely-moving rats as measured by intracerebral microdialysis. Psychopharmacology (Berl) 102: 156-162.

Davis C (1997). Eating disorders and hyperactivity: a psychobiological perspective. Can J Psychiatry 42: 168-175.

De Vry J, Jentzsch KR, Kuhl E, Eckel G (2004). Behavioral effects of cannabinoids show differential sensitivity to cannabinoid receptor blockade and tolerance development. Behav Pharmcol 15: $1-12$.

Delgado MR (2007). Reward-related responses in the human striatum. Ann N Y Acad Sci 1104: 70-88.

Dixon DP, Ackert AM, Eckel LA (2003). Development of, and recovery from, activity-based anorexia in female rats. Physiol Behav 80: 273-279.

Drewnowski A, Pierce B, Halmi KA (1988). Fat aversion in eating disorders. Appetite 10: 119-131.

Epling WF, Pierce D, Stefan L (1983). A theory of activity-based anorexia. Int J Eat Disord 3: 26-46.

Fernstrom MH, Weltzin TE, Neuberger S, Srinivasagam N, Kaye WH (1994). Twenty-four-hour food intake in patients with anorexia nervosa and in healthy control subjects. Biol Psychiatry 36: $696-702$.

Fisk JE, Montgomery C, Wareing M, Murphy PN (2006). The effects of concurrent cannabis use among ecstasy users: neuroprotective or neurotoxic? Hum Psychopharmacol 21: 355-366.

Frank GK, Bailer UF, Henry SE, Drevets W, Meltzer CC, Price JC et al (2005). Increased dopamine D2/D3 receptor binding after recovery from anorexia nervosa measured by positron emission tomography and [11c]raclopride. Biol Psychiatry 58: 908-912.

Frieling H, Albrecht H, Jedtberg S, Gozner A, Lenz B, Wilhelm J et al (2009). Elevated cannabinoid 1 receptor mRNA is linked to eating disorder related behaviour and attitudes in females with eating disorders. Psychoneuroendocrinology 34: 620-624.

Frisbie JH, Aguilera EJ (1995). Diazepam and body weight in myelopathy patients. J Spinal Cord Med 18: 200-202.

Gardner EL, Paredes W, Smith D, Donner A, Milling C, Cohen D et al (1988). Facilitation of brain stimulation reward by delta 9-tetrahydrocannabinol. Psychopharmacology (Berl) 96: 142-144.

Garfinkel PE, Moldofsky H, Garner DM (1979). The stability of perceptual disturbances in anorexia nervosa. Psychol Med 9: 703-708.

Gross H, Ebert MH, Faden VB, Goldberg SC, Kaye WH, Caine ED et al (1983). A double-blind trial of delta 9-tetrahydrocannabinol in primary anorexia nervosa. J Clin Psychopharmacol 3: 165-171.

Herkenham M, Lynn AB, de Costa BR, Richfield EK (1991a). Neuronal localization of cannabinoid receptors in the basal ganglia of the rat. Brain Res 547: 267-274.

Herkenham M, Lynn AB, Johnson MR, Melvin LS, de Costa BR, Rice KC (1991b). Characterization and localization of cannabiniod receptors in rat brain: a quantitative in vitro autoradiographic study. J Neurosci 11: 563-583.

Hillebrand JJ, Heinsbroek AC, Kas MJ, Adan RA (2006). The appetite suppressant d-fenfluramine reduces water intake, but not food intake, in activity-based anorexia. J Mol Endocrinol 36: $153-162$.

Hillebrand JJ, Koeners MP, de Rijke CE, Kas MJ, Adan RA (2005a). Leptin treatment in activity-based anorexia. Biol Psychiatry 58: $165-171$
Hillebrand JJ, van Elburg AA, Kas MJ, van Engeland H, Adan RA (2005b). Olanzapine reduces physical activity in rats exposed to activity-based anorexia: possible implications for treatment of anorexia nervosa? Biol Psychiatry 58: 651-657.

Jatoi A, Windschitl HE, Loprinzi CL, Sloan JA, Dakhil SR, Mailliard JA et al (2002). Dronabinol versus megestrol acetate versus combination therapy for cancer-associated anorexia: a North Central Cancer Treatment Group study. J Clin Oncol 20: 567-573.

Jbilo O, Ravinet-Trillou C, Arnone M, Buisson I, Bribes E, Peleraux A et al (2005). The $\mathrm{CB}_{1}$ receptor antagonist rimonabant reverses the diet-induced obesity phenotype through the regulation of lipolysis and energy balance. FASEB J 19: 1567-1569.

Kaye W (2008). Neurobiology of anorexia and bulimia nervosa. Physiol Behav 94: 121-135.

Kaye WH, Barbarich NC, Putnam K, Gendall KA, Fernstrom J, Fernstrom $\mathrm{M}$ et al (2003). Anxiolytic effects of acute tryptophan depletion in anorexia nervosa. Int J Eat Disord 33: 257-267.

Kirkham TC, Williams CM (2001). Endogenous cannabinoids and appetite. Nutr Res Rev 14: 65-86.

Kirkham TC, Williams CM, Fezza F, Di Marzo V (2002). Endocannabinoid levels in rat limbic forebrain and hypothalamus in relation to fasting, feeding, and satiation: stimulation of eating by 2-arachidonoyl glycerol. Br J Pharmacol 136: 550-557.

Koch JE (2001). $\bigoplus^{9}$-THC stimulates food intake in Lewis rats: effects on chow, high-fat, and sweet high-fat diets. Pharmacol Biochem Behav 68: 539-543.

Kojima S, Nagai N, Nakabeppu Y, Muranaga T, Deguchi D, Nakajo M et al (2005). Comparison of regional cerebral blood flow in patients with anorexia nervosa before and after weight gain. Psychiatry Res 140: 251-258.

Kola B, Hubina E, Tucci SA, Kirkham TC, Garcia EA, Mitchell SE et al (2005). Cannabinoids and ghrelin have both central and peripheral metabolic and cardiac effects via AMP-activated protein kinase. J Biol Chem 280: 25196-25201.

Lewis DY, Brett RR (2010). Activity-based anorexia in C57/BL6 mice: effects of the phytocannabinoid, big up tri, open(9)tetrahydrocannabinol (THC) and the anandamide analogue, OMDM-2. Eur Neuropsychopharmacol 20: 622-631.

Lihn AS, Jessen N, Pedersen SB, Lund S, Richelsen B (2004). AICAR stimulates adiponectin and inhibits cytokines in adipose tissue. Biochem Biophys Res Commun 316: 853-858.

Liu Y, Wan Q, Guan Q, Gao L, Zhao J (2006). High-fat diet feeding impairs both the expression and activity of AMPKa in rats' skeletal muscle. Biochem Biophys Res Commun 339: 701-707.

Mahler SV, Smith KS, Berridge KC (2007). Endocannabinoid hedonic hotspot for sensory pleasure: anandamide in nucleus accumbens shell enhances 'liking' of a sweet reward. Neuropsychopharmacology 32: 2267-2278.

Malone DT, Taylor DA (1999). Modulation by fluoxetine of striatal dopamine release following Delta9-tetrahydrocannabinol: a microdialysis study in conscious rats. Br J Pharmacol 128: 21-26.

McKinney DL, Cassidy MP, Collier LM, Martin BR, Wiley JL, Selley DE et al (2008). Dose-related differences in the regional pattern of cannabinoid receptor adaptation and in vivo tolerance development to delta9-tetrahydrocannabinol. J Pharmcol Exp Ther 324: 664-673.

Monteleone P, Matias I, Martiadis V, De Petrocellis L, Maj M, Di Marzo V (2005). Blood levels of the endocannabinoid anandamide are increased in anorexia nervosa and in binge-eating disorder, but not in bulimia nervosa. Neuropsychopharmacology 30: $1216-1221$.

Naruse T (1994). Effects of repeated intravenous administration of diazepam on food intake in rats. Fundam Clin Pharmacol 8: 379-384.

Patel S, Hillard CJ (2006). Pharmacological evaluation of cannabinoid receptor ligands in a mouse model of anxiety: further evidence for an anxiolytic role for endogenous cannabinoid signaling. J Pharmcol Exp Ther 318: 304-311. 
Patel SM, Ebenezer IS (2008). The effects of acute multiple intraperitoneal injections of the GABAB receptor agonist baclofen on food intake in rats. Eur J Pharmacol 601: 106-110.

Perwitz N, Fasshauer M, Klein J (2006). Cannabinoid receptor signaling directly inhibits thermogenesis and alters expression of adiponectin and visfatin. Horm Metab Res 38: 356-358.

Pirke KM, Broocks A, Wilckens T, Marquard R, Schweiger U (1993). Starvation-induced hyperactivity in the rat: the role of endocrine and neurotransmitter changes. Neurosci Biobehav Rev 17: 287-294.

Rossmeisl M, Flachs P, Brauner P, Sponarova J, Matejkova O, Prazak $\mathrm{T}$ et al (2004). Role of energy charge and AMP-activated protein kinase in adipocytes in the control of body fat stores. Int J Obes Relat Metab Disord 28(Suppl 4): S38-S44.

Routtenberg A, Kuznesof AW (1967). Self-starvation of rats living in activity wheels on a restricted feeding schedule. J Comp Physiol Psychol 64: 414-421.

Santel S, Baving L, Krauel K, Münte TF, Rotte M (2006). Hunger and satiety in anorexia nervosa: fMRI during cognitive processing of food pictures. Brain Res 1114: 138-148.

Siegfried Z, Berry EM, Hao S, Avraham Y (2003). Animal models in the investigation of anorexia. Physiol Behav 79: 39-45.

Stefanidis A, Verty ANA, Allen AM, Owens NC, Cowley MA, Oldfield BJ (2009). The role of thermogenesis in antipsychotic drug-induced weight gain. Obesity (Silver Spring) 17: $16-24$.

Takano A, Shiga T, Kitagawa N, Koyama T, Katoh C, Tsukamoto E et al (2001). Abnormal neuronal network in anorexia nervosa studied with I-123-IMP SPECT. Psychiatry Res 107: 45-50.

Taylor DA, Sitaram BR, Elliot-Baker S (1988). Effects of $\Delta^{9}$-tetrahydrocannabinol on release of dopamine in the corpus striatum of the rat. In: Chesher G, Consore P, Musty R (eds). Marijuana: An International Research Report. Australian Government Publishing Service: Canberra pp 405-408.
Treasure J, Campbell I (1994). The case for biology in the aetiology of anorexia nervosa. Psychol Med 24: 3-8.

Valjent E, Mitchell JM, Besson MJ, Caboche J, Maldonado R (2002). Behavioural and biochemical evidence for interactions between Delta 9-tetrahydrocannabinol and nicotine. Br J Pharmacol 135: 564-578.

Verhagen LA, Luijendijk MC, Hillebrand JJ, Adan RA (2009a). Dopamine antagonism inhibits anorectic behavior in an animal model for anorexia nervosa. Eur Neuropsychopharmacol 19: 153-160.

Verhagen LA, Luijendijk MC, Korte-Bouws GA, Korte SM, Adan RA (2009b). Dopamine and serotonin release in the nucleus accumbens during starvation-induced hyperactivity. Eur Neuropsychopharmacol 19: 309-316.

Verty ANA, Allen AM, Oldfield BJ (2009). The effects of rimonabant on brown adipose tissue in rat: implications for energy expenditure. Obesity (Silver Spring) 17: 254-261.

Verty ANA, McGregor IS, Mallet PE (2004). The dopamine receptor antagonist SCH 23390 attenuates feeding induced by $\bigoplus^{9}$-tetrahydrocannabinol. Brain Res 1020: 188-195.

Verty ANA, McGregor IS, Mallet PE (2005). Paraventricular hypothalamic $\mathrm{CB}_{1}$ cannabinoid receptors are involved in the feeding stimulatory effects of $\bigoplus^{9}$-tetrahydrocannabinol. Neuropharmacology 49: 1101-1109.

Vitousek K, Manke F (1994). Personality variables and disorders in anorexia nervosa and bulimia nervosa. J Abnorm Psychol 103: 137-147.

Walsh BT, Devlin MJ (1998). Eating disorders: progress and problems. Science 280: 1387-1390.

Williams CM, Kirkham TC (2002a). Observational analysis of feeding induced by Delta9-THC and anandamide. Physiol Behav 76: $241-250$.

Williams CM, Kirkham TC (2002b). Reversal of $\bigoplus^{9}$-THC hyperphagia by SR141716 and naloxone but not dexfenfluramine. Pharmacol Biochem Behav 71: 341-348. 